\title{
Sobre la portada
}

L a ciudad de Puebla posee en su centro histórico un sinnúmero de edificaciones consideradas joyas de la arquitectura colonial y del siglo XIX. Su traza ortogonal es, sin duda, una de sus características más conocidas, así como su singular fundación de "ciudad española". En sus calles se mezclan construcciones civiles y religiosas que dan cuenta de un rico pasado lleno de historias, leyendas y anécdotas. Uno de los rincones más emblemático de la ciudad es la Plaza de la Democracia, en la 4 Sur, entre las calles 3 Oriente y Juan de Palafox y Mendoza. Aquí se encuentra el templo de la Compañía y a su lado el edificio de la rectoría de la Benemérita Universidad Autónoma de Puebla (BUAP), conocido coloquialmente como "El Carolino". Esta calle, ahora peatonal, es uno de los espacios poblanos más bellos y representativos de la ciudad no sólo por estos dos extraordinarios edificios sino también por la larga tradición con que cuenta.

La imagen que se muestra en la portada es una tarjeta postal. La fotografía fue tomada probablemente en la década de los veinte o treinta del siglo pasado, no se conoce el nombre del autor pero se situó de sur a norte y desde la esquina de la 3 Oriente realizó su encuadre. Del lado derecho se puede apreciar el costado de la iglesia de la Compañía con su imponente torre sur, apenas se logra ver su portada barroca con sus arcos, pero lo que se distingue claramente es el arco lateral de medio punto y su reja. El primer plano es el frente del edificio de dos plantas del entonces Colegio del Estado, hoy rectoría de la BUAP, con sus siete balcones con herrería en la parte superior y en la inferior cinco ventanales con dos portones, cada uno al extremo de la fachada, siendo la entrada principal el portal al lado del templo. En la parte superior, justo al centro, se encuentra un asta bandera. A la izquierda de la imagen apenas se ve una parte saliente de la construcción del que fuera el hotel Jardín, hoy hotel Colonial, un poco más atrás se aprecia la esquina de la construcción que se localiza en la intersección de la 4 Norte y la calle del Ayuntamiento. ${ }^{1}$ Se destacan unos toscos

${ }^{1}$ La calle tuvo varios nombres: en 1601 se denominó, "que va del Portal de la Audiencia para la iglesia de los Teatinos"; para 1734 "de la Compañía de Jesús”; de finales del siglo XVIII se le conoció como "de la Compañía"; a partir de 1864 se le nombró "Jarcierías" o de la "Compañía", a partir de la nomenclatura del siglo xx cambio de nombre por avenida del Ayuntamiento, después Maximino Ávila Camacho y a partir del año 2000 (i) Juan de Palafox y Mendoza. La nomenclatura actual de las 
postes de luz que dejan ver las curvas propias del árbol que fue transformado en sostén de cables de energía por medio de cuatro soportes transversales en la parte superior. ${ }^{2}$ Apenas unas cuantas personas aparecen en la imagen, algunas borrosas y al fondo se ven las casas de la acera oriente de la 4 Norte, prácticamente vacía de peatones hecho impensable hoy día. La foto fue tomada por la tarde pues la sombra del edificio del hotel Jardín cubre media calle, en la que se pueden ver las vías del tranvía que fue suprimido en 1929. ${ }^{3}$ En el pie de la foto se anotó: "La Compañía y Colegio del Estado Pue [borroso] 38". La fotografía seguramente formó parte de un grupo de postales de la ciudad y de ahí la identificación de las construcciones y el número.

\section{LOS EDIFICIOS}

Este rincón de la Angelópolis fue desde muy temprano un espacio jesuita en donde se impartió la educación de conocimientos y del alma. En 1578 a instancias del Ayuntamiento y con la valiosa contribución del rico comerciante en grana, Melchor de Covarrubias, se fundó el Colegio del Espíritu Santo. A partir de 1790 y hasta 1820 se transformó en Colegio Carolino. En el siglo XIX tuvo varias denominaciones: entre 1820-1821, Real Colegio del Espíritu Santo; Imperial Colegio entre 1821 y 1825. A partir del 28 de mayo de 1825 por decreto se transformó en Colegio del Estado, con un breve cambio durante el segundo imperio (1864-1867), en que se le conoció como Colegio Imperial del Espíritu Santo. Ya en el siglo xx, en el año de 1937, por iniciativa de Maximino Ávila Camacho, gobernador del estado, se trasformó en Universidad de Puebla. La autonomía se conquistó hasta 1956 y de 1987 en adelante el Congreso del estado declaró Benemérita a la Universidad Autónoma de Puebla. ${ }^{4}$

Por su parte, el templo de la Compañía, aunque se estrenó en el año de 1600 con una celebración que duró nueve días, se terminó de construir hasta 1767 , cuando el 28 de febrero se inauguró el pórtico y las torres, hasta el primer

calles data de 1917. Véase, Hugo Leich, Las calles de Puebla. Estudio bistórico, Imprenta A. Mijares y Hno., Puebla, 1934, pp. Xxvi y 202-203.

${ }^{2}$ La luz eléctrica se introdujo en la capital poblana el día 2 de abril de 1888. José de Mendizábal Tamborrel, Los almanaques poblanos y las efemérides de Puebla, 1519-1833, Dirección de Fomento Editorial-BUAP, Puebla, 2009, p. 111.

${ }^{3}$ Es muy probable que años después de suprimir los tranvías las vías permanecieran en las calles.

${ }^{4}$ Nydia E. Cruz Barrera, "El Colegio del Estado, testimonios de la vida en un establecimiento para la educación. Estudio introductorio" en Alberto Pérez Peña, El Colegio del Estado de Puebla. En el primer centenario de su vida civil, 1925 (facsímil), Vicerrectoria de Investigación y Estudios de PosgradoBUAP, 1998, Puebla, p. XIv. Enrique Agüera Ibáñez y Carlos Contreras Cruz (eds.), Alma Mater, BUAP, Puebla, 2011, pp. 119-21. 


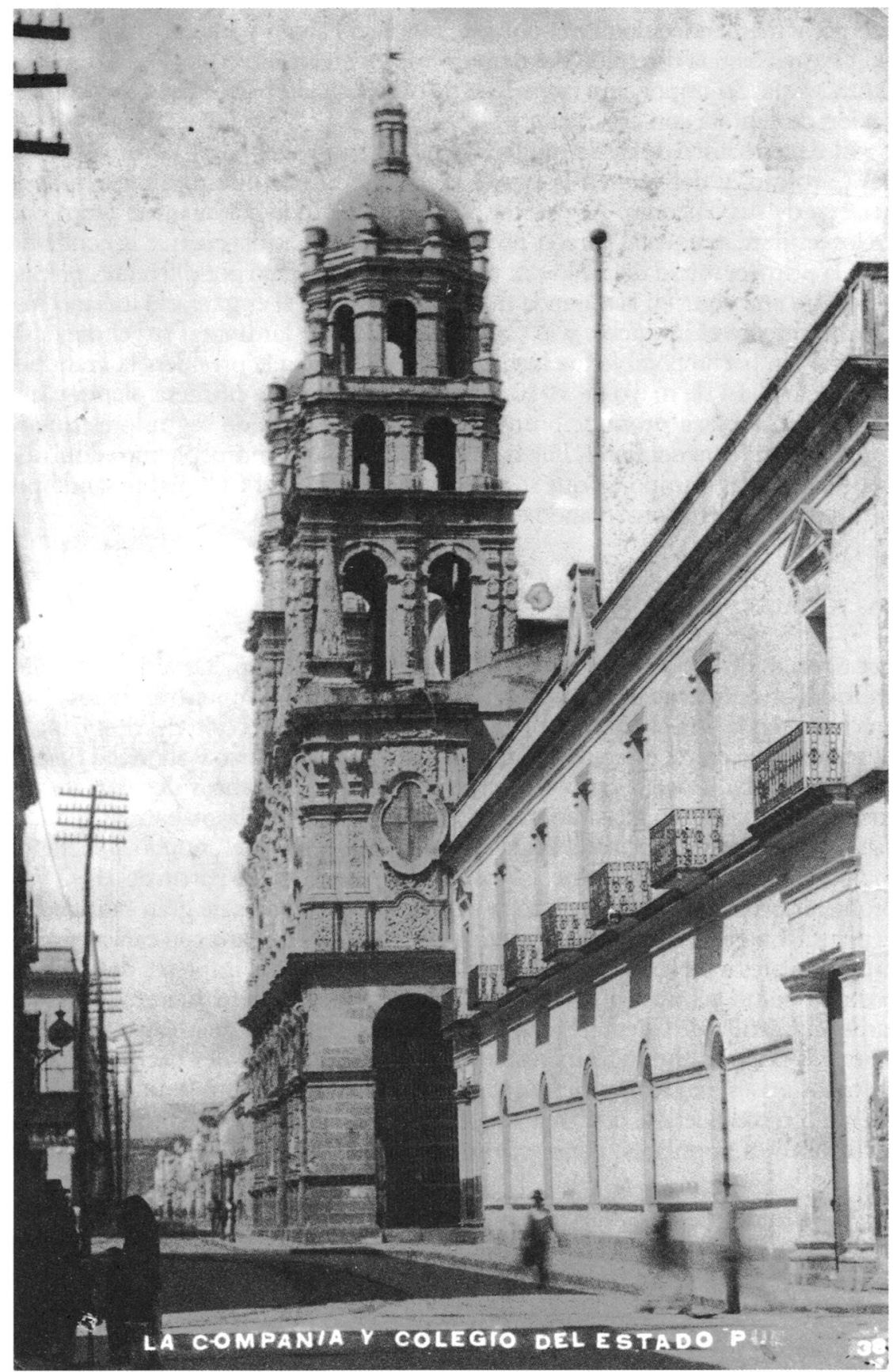

El templo de la Compañia y el Colegio del Estado boy Benemérita Universidad Autónoma de Puebla, publicada en Carlos Contreras Cruz y José Luis Olazo García (eds.), Postales de Puebla, Dirección de Fomento Editorial-Buap, Puebla, 2011. 
cuerpo, y fue bendecido por el obispo Francisco Fabián y Fuero. ${ }^{5}$ La construcción estuvo bajo la dirección del maestro mayor en arquitectura José Miguel de Santa María. Su imponente fachada es de composición barroca con una combinación de cantera con argamasa.

El tercer edifico de este singular rincón poblano es el hotel Jardín, al frente del Carolino, y del que en la postal apenas se puede distinguir parte de la herrería de sus balcones. Al parecer durante el periodo colonial fue propiedad de los jesuitas, aunque al parecer no se ha encontrado evidencia que lo confirme. Para la primera mitad del siglo XIX tuvo varios usos y pasó por diferentes propietarios, sin embargo, en la segunda mitad del siglo XIX el empresario italiano José Brachetti rentó el inmueble y lo convirtió en el hotel Jardín, tal vez el mejor de Puebla. Un hecho notable fue la visita del candidato a la presidencia Francisco I. Madero el 14 de mayo de 1910. Desde el balcón de la primera planta y que da justo a la plaza pronunció un discurso a sus miles de seguidores que se congregaron fuera del hotel. Fue hasta 1935 cuando el inmueble fue adquirido por Manuel del Campo en que se transformó en el hotel Colonial pasando por varios dueños pero conservando el nombre hasta hoy día.

\section{LAS POSTALES}

Fue a finales de 1860 cuando aparecieron en Europa las primeras tarjetas postales emitidas oficialmente por las oficinas de correos, tenían impreso el franqueo en una cara y en la otra el espacio para escribir y anotar la dirección del destinatario. El mensaje era corto, estaba a la vista, su costo era económico y ahorraba tiempo al que enviaba. Poco a poco se fueron añadiendo elementos decorativos y/o comerciales haciendo a las tarjetas objetos en donde se plasmaban las tendencias artísticas de una sociedad ávida de tener "recuerdos" del mundo, generando toda una industria de las tarjetas postales ya ilustradas. A partir de 1880 va a proliferar principalmente en Europa el gusto de las tarjetas de gran cantidad de géneros. ${ }^{6}$ En 1882 se editó la primera tarjeta postal mexicana con características muy similares a las europeas y estadunidenses: en una cara impresos dos timbres postales de un centavo ilustrados con la imagen de Benito Juárez. Años más tarde, el Castillo de Chapultepec y la catedral de la ciudad de México fueron las primeras ilustraciones que aparecieron en las tarjetas postales nacionales, eran en tonos grises, negros, verdes o sepias. ${ }^{7}$ La fotografía pronto se integró dando cuenta con todo detalle de diversos temas urbanos como los mercados, los tipos y costumbres populares, paisajes, ruinas prehispánicas, felicitaciones, artistas

\footnotetext{
${ }^{5}$ Mendizábal, Almanaques, 2009, p. 38.

${ }^{6}$ Véase a Isabel Fernández Tejedo, Recuerdo de México. La tarjeta postal mexicana, 1882-1930, Banobras, México, 1995, p. 13.

7 Ibid., p. 14.
} 
de la farándula, celebraciones, etc. Entre los fotógrafos que se integraron a esta moda podemos nombrar a C. B. Waite, Guillermo Kahlo y Hugo Brehme, entre otros. Varias fueron las principales casas editoras y distribuidoras de postales; por nombrar algunas tenemos: la Librería de la Vda. de C. Bouret, J. e I. G. Hatton, J. Granar, La Joyita e Iturbide Curios Store, en la ciudad de México. En Xalapa se tiene La Sorpresa y M. Alba y a Carlos V. Toussaint en Puebla. ${ }^{8}$ Buena parte de las postales integraron las fotos en toda una cara cobrando importancia no sólo el texto sino la imagen que se enviaba.

Para finales de la centuria decimonónica a instancias de la Unión Postal Universal se normó el tamaño de las tarjetas postales a $9 \times 4 \mathrm{~cm}$., formato que se conservó hasta mediados del siglo pasado. Para 1906, el reverso de la tarjeta se dividió en dos mitades: la derecha para escribir la dirección del destinatario y colocar la estampilla y la izquierda para el mensaje. Las tarjetas a lo largo del siglo xx pasaron por diferentes etapas, pero hoy en día con las comunicaciones del ciberespacio el mensaje corto se envía por "mail", por "face" o se "tuitea", no obstante aún podemos encontrar estos recuerdos en muchos locales. Las tarjetas antiguas forman parte de colecciones, no sólo por su belleza sino porque son testimonio de la imagen del pasado.

En un esfuerzo de la BUAP y del Program for Mexican Culture and Society in Puebla (PMCSP) se ha conformado un acervo fotográfico del que forman parte una colección de postales con las que se publicó Postales de Puebla, " "La Compañía y Colegio del Estado..." forma parte de esta colección.

Carlos Contreras Cruz José Luis Olazo García Benemérita Universidad Autónoma de Puebla

${ }^{8}$ Ibid., pp. 39-40.

${ }^{9}$ Carlos Contreras Cruz y José Luis Olazo García (eds.), Postales de Puebla, Dirección de Fomento Editorial-BUAP, Puebla, 2011. 